\title{
Analysis on the Legal Regulation of Personal Information Commercialization in the Era of Cloud Computing
}

\author{
Rui Zhao ${ }^{1}$, Ben-zhuo Fu², Hai-cheng $\mathrm{Zhang}^{3}$ \\ ${ }^{1}$ Department of Business, Qinhuangdao Institute of Technology, Qinhuangdao, Hebei, China \\ ${ }^{2}$ Department of Sports, Qinhuangdao Institute of Technology, Qinhuangdao, Hebei, China \\ ${ }^{2}$ Dean's Office, Qinhuangdao Institute of Technology, Qinhuangdao, Hebei, China \\ Lwdxdf5@126.com, Lwdxdf4@126.com
}

\begin{abstract}
With the development of Internet and electronic business in the era of cloud computing, the commercialization of personal information is inevitable. The protection of the traditional right of privacy for the personal information has some shortcomings. China should learn the theory and practical experience from Germany, Hongkong and other countries. In the construction of legal system for the regulation of personal information commercialization, we should establish "personal information right" in the legislation, fully respect and protect individual information rights, and at the same time, and give consideration to the social and public interests. Furthermore, we should make institutional arrangementsto establish specialized regulatory agencies, Internet industry self-regulation, technical development and personal protection consiousness.
\end{abstract}

Index Terms - Personal information; Commercialization; Legal Regulation

\section{Introduction}

Many people intangibly find that our own has been betrayed, because there are unbearable sales promotion phone, spam messages, spam e-mails. An editorial article from Chinese Economic times, "Commercialization of Personal Data Needs Legal Statute" aroused my thinking. As the paper said, the commercialization of the personal data should not be great scourges. On the contrary, we should use legal means to strictly regulate the ratio completely blocked perhaps more rational and feasible. Therefore, this paper will make an an analysis on the legal regulation of personal information commercialization in the era of cloud computing.

\section{Personal Information Commercialization in the Era of Cloud Computing}

Since 2006 Google CEO Eric Schmidt first put forward the concept of Cloud Computing, Google has started computing plan in the promotion of clouds all around the world. Some of the world famous IT companies, such a AA s Yahoo, HP, Intel and domestic Baidu, have joined the "cloud" of the industry. Services provided by Cloud Computing are required to have a large number of users' participation. Cloud service providers collect relevant information and data to verify the identity of the individual user or to provide personalized service. The collection, storing massive user personal information for their own development and the enterprise except for user information to explore the commercial value of fine analysis, will be out of business cooperation and foreign transfer or sell the user database.
A. Personal Information, A Kind of Information Commodity

Personal information is recorded as the natural person, including personal date of birth, gender, hobby, occupation, family situation, income, health status and so on. In the traditional economy is no more than existing as a distinct individual identification system. In the information society, businessmen are very interested in these personal information. For example, from the date of birth, businesses can know the age of his customers. A certain age stage customer groups, such as "after 70", "after 80", have some common characteristics and taste because of the similar historical background. Therefore, the businessman can be targeted to launch related products. America sociologist Naisbitt said what plays a decision role in the information society is information knowledge matered by most people rather than capital, but most people in the hands of the master. Modern network and advanced computer technology makes information commodity with depth and wider development, and personal information and the commodity value was discovered, which becomes a kind of capital business profit.

\section{B. Personal Information Goods Mainly Refers to the Collection of Personal Information}

The value of single personal information is very limited to the businessman. The collection of personal information in accordance with the method of a scientific, professional, form a sorted or "two development" after the database for business. A variety of commercial behavior provides a basis and reference value, thus become a part of corporate intangible assets. And the number of the more personal information data is the aggregate value is higher, and the meaning of the $1+1>2$ is exactly the same.

\section{The Real Problems Facing the Personal Information Commercialization in Cloud Computing Era}

The personal information of users of network are mainly collected through the following four ways: firstly, to be collected in the user registration or in some network activities; secondly, the user cookies; thirdly, some unscrupulous companies or individuals through the tool to pry special or give the user the Trojans implant; fourthly, the computer system the hacker inbreaks directly related departments.

As can be seen, in addition to the first way, the other three ways are collected without the knowledge of users; and, 
even if it is the first method, personal information may be collected may imperceptibly.

Therefore, the law risk of personal information commercialization is very large, even relating to criminal responsibility. And in the cloud model, personal information is stored in a large cloud, cloud technology based on the limitation, safety is the problem.

In 2010, Facebook's 1 million users information was leaked; in 2010, 114 thousand iPad users information was leaked AT\&T sites; in the same year, MySpace was accused of leaking privacy to advertising companies; at the same time, the user data, Baidu 360 client, Dangdang.com and many other Internet Co news was leaked. Then the article mentioned at the end of 2011 in China during the CSDN, such as the end of the world large-scale web site user information leakage incident really let everyone terrified. These phenomena reflect the cloud computing era of network user personal information management. $\mathrm{Tttt}$ the real problem facing material commercial: illegal collection of personal information, personal information privacy are not effectively protected, a security and personal information data is worrying; at the same time, we also see, the network service provider based on own development very willing to through various methods to collect personal information, this is a small business big lucrative, because individuals can hardly get any proportion from the interest, the personality right even can not be guaranteed, individual's subject status need to be legally further clarified.

\section{Resolve of Personal Information Commercialization in the Cloud Computing Era}

\section{A. Personal Information, A Kind of Information Commodity}

Since 1890 two American scholars Brandeis (Brandeis) and Warren (Wallen) in the "Harvard Law Review" published a famous article entitled The Right to Privacy, and this paper for the first time used the word of "privacy". The right of privacy has aroused extensive attention of theory and practice. The network is in the ascendant, black caricature of the famous American magazine "New York guest" once publish humor: "On the Internet, nobody knows you're a dog", a way to the virtual network. This highlighted the true information of network user privacy and privacy properties. In addition to a variety of privacy in real life, can not become a privacy "name, gender, height and other" have become the Internet privacy in real life. But with the strengthening of individual subject consciousness and right consciousness, strengthen the legal protection of the right of privacy are increasingly high. The United States through a series of case will its rise to the constitutional rights, China also in 2009 through the "tort liability law" established the right of privacy.

Although the law has increased the protection of privacy, a lot of content of the personal information can be included, but with the development of network technology and ecommerce, personal data displayed great commercial value is the traditional theory of the right of privacy is unexpected. The right of privacy as a specific right of personality, and personal related without direct property content. Put forward the personal information and privacy right just perfect complementary. The center of gravity of privacy system lies in the prevention of personal secret is not disclosed, lived in peace and not to be disturbed, more reflect a kind of passive defense measures. While the personal information right is a kind of people actively use and control their own information, and can produce the interests of property, the personal information commercialization rights. In fact, many celebrities especially the people of entertainment circle at through a variety of methods, the use of their personal information including privacy to get attention, to raise prices, is a typical personal information commercialization.

In our country, the personal information right has also been law recognized by everyone. Professor Wang Liming said: "The personal information right refers to a control person for their own information, which is not entirely a negative to the exclusion of others the right to use, more cases is an autonomous control information appropriate communication rights."

\section{B. From Individual Rights to Balance Between Individual Rights And Public Interests}

At the beginning of 2011, the EU intends to revise the "data protection directive", in order to better reflect the new changes of personal data protection network service incidental, to promote technological innovation. President Jonathan JOKO of the European competition and Technology Association said, in the cloud model, with the help of data protection method effectively, enterprises can maximize the cloud pattern brings the commercial potential, continuous innovation and performance so as to realize the technology growth. 2011 year in June, the Senate voted California American rejected a request from the social networking site without authorization to share user data information without permission of the bill. And American California state has always been to strict examination and supervision of personal privacy information is known. The state was America first request enterprise must inform the user relates to information security risk of credit card numbers and other personal state. These messages are revealed: the new problems of legislative departments have been aware of cloud computing brings to the personal information protection, and ready to reform the law to deal with new problems.

\section{Commercial Value of the Personal Information}

The personality as a "person" as a legal subject qualification, as the basic everyday, cannot be transferred, sold. Personal information commercialization is the personal information of commercial value, rather than the individual personality. As a famous movie star paid the image of license to a vendor for the packing of the products, the personality right -- the right of portrait did not transfer, but its own public influence based on, the portrait has already generated considerable economic value, it can be a portrait of interest temporary license to others. 


\section{Construction of Law System of Regulation of Personal Information Commercialization in China's Cloud Computing Era}

A. The Introduction of Personal Information Protection Law As Soon As Possible, to Provide Legal Support to Personal Information Commercialization

Although our country in 2009 introduced amendments to the penal code (seven), adding to sell illegally providing personal information of citizens and the crime of illegal theft of personal information of citizens against crime, serious crime of illegally selling or providing personal information of citizens information monopoly of the criminal law, the black chain hit the underground personal information circulation, powerful to safeguard the rights of individual citizens. In the civil field, China's only "tort law" on the "privacy" civil interest provisions may apply, as previously mentioned, the theory about the protection of privacy cannot solve the personal information of the current. Therefore, the introduction of personal information protection law imminent.

Personal information protection law to deal with personal information right to make specific provisions, clearly the rights and obligations of subjects related to personal information commercialization process. Information I as the personal information of the original obligee, is always the right to control personal information goods circulation decision right and the transfer process, the personal information collection, transfer and utilization must obtain personal consent and know the situation of the use of. Of course, the law may be in the special case of the rights of the individual to make the proper limit. Human is not only the right of personal information data collector, two developers subject in the personal information transfer process is also the obligor, to some extent they are personal information right (to the personal information database rights) subject; at the same time they also bear the guarantee the security of personal information obligation.

\section{B. The Establishment of A Special Personal Information Supervision Authorities, And the Protection of Personal Information Commercialization Orderly}

In the personal information commodity circulation process, person with respect to commercial enterprises are too weak to protect their personal information rights more difficult, must have the specialized agencies to undertake the task of supervision. The British according to the 1998 "data protection law" set up the office of the Commissioner for data protection, data protection Commissioners can perform notification to send in violation of the data protection act data controller, requiring them to take corresponding measures to protect the interests of the owner of rights. Germany according to the 2003 "Federal Data Protection Act" to establish Federal Data Protection Commissioner, independent and the handling of personal data protection and fair transaction.
C. Strengthening the Industry self-regulation, And provide A Good Environment for Personal Information Commercialization

Now a large number of illegal trading personal information is through the online transactions, or a large amount of personal information from the network enterprise operators leaked, the network became illegal personal information transaction of the hardest hit areas. This enterprise and Internet itself indifference, on the rights of the individual network users a sense of social responsibility is not strong. By the end of 2011, CSDN hacking, 6000000 users registered email and password is compromised leading to a large number of user information leakage, it is reported the reason is the enterprise did not take any security measures! Although after these enterprises recognize the error and punished, but still cause for concern and thinking, strengthen the self-discipline of the Internet industry has a long way to go! In practice American has always attached importance to the industry selfdiscipline, non-profit institutions such as Truste to meet different discipline website of standard certification, to the personal information collection, utilization of self-discipline behavior effectively. At the same time, hope to strengthen selfdiscipline of Internet enterprises, will be effectively the interests of enterprises based on protecting the legitimate rights and interests of the user base.

D. The Development of Data Protection of Personal Information, Technology to Provide Personal Information Commercialization Support

Personal information commercialization problem is a new problem appeared with the development of technology, we see a lot of violation of personal information of the act itself is the high technology, such as the Trojan horse program etc.. Let the law to the law, technology to technology. Relying solely on the law of compulsory norms often reach the good social effect, must at the same time, the development of personal information protection technology.

E. Strengthening Network User's Personal Ego to Protect Consciousness, And Building Positive Network Order

Due to the influence of traditional culture, China's network user's sense of personal rights, right of privacy awareness are relatively weak, so the user individual first to enhance the awareness of individual rights, to recognize that part of their own information belongs to own right, can not be free to use other people; at the same time to strengthen the awareness of personal protection, guard their personal information collected by illegal or use, in particular to their privacy content. At the same time, by the self and people, users have formed to respect the rights of others and a sense of privacy, not spy on others information and privacy, form the good moral atmosphere of mutual respect.

The relevant departments should also through various channels, publicity about Internet law and morality, education and infection of the masses of network users, improve the user consciousness of legal rights and the rule of law consciousness, advocate all civilized Internet, self-discipline 
in the formation of the network, to abide by rules of network law and moral construction of the network order, positively.

\section{Conclusion}

With the development of Internet and electronic business in the era of cloud computing, the commercialization of personal information is inevitable. The protection of the traditional right of privacy for the personal information has some shortcomings. China should learn the theory and practical experience from Germany, Hongkong and other countries. In the construction of legal system for the regulation of personal information commercialization, we should establish "personal information right" in the legislation, fully respect and protect individual information rights, and at the same time, and give consideration to the social and public interests. Furthermore, we should make institutional arrangementsto establish specialized regulatory agencies, Internet industry self-regulation, technical development and personal protection consiousness.

\section{References}

[1] Michael Armbrust,Armando Fox,Rean Griffith,et al.Above the clouds:A Berkeley view of cloud computing. EECS-2009-28 . 2009

[2] Choubey R,Dubey R,Bhattacharjee J.A Survey on Cloud Comput-ing Security Challenges andThreats. Int.Journal on Computer Scienceand Engineering . 2011

[3] George Jiang."Rain Or Shine:Fair and Other Non-infringing Uses in the Context of Cloud Computing". J.Legis . 2010

[4] Bowen,Janine Anthony.Cloud Computing:Issues in Data Privacy/Security and Commercial Considerations. The Computer\&Internet Lawyer . 2011

[5] Shilpashree Srinivasamurthy.Survey on Cloud Computing Security. CloudCom . 2010

[6] Traian Andrei.Cloud Computing Challenges and Related Security Issues. http://www.cse.wustl.edu/-jain/cse571-09/ftp/cloud/index.html . 2009 